\title{
Pesquerías ribereñas en Baja California
}

\author{
Ana María Avilés Muñoz \\ Leticia Figueroa Ramírez \\ Instituto de Investigaciones Sociales \\ Universidad Autónoma de Baja California
}

\begin{abstract}
Resumen
El presente artículo tiene como objetivo establecer los resultados de la investigación sobre las formas de organización y producción de las pesquerías en Baja California, su grado de desarrollo y la participación del Estado en relación con el proceso de consolidación, desarrollo, requerimientos específicos de las pesquerías y estímulos para la generación de productos pesqueros de bajo valor comercial o de consumo mayoritario. Este trabajo se sirvió de dos tipos de investigación: la documental y la de campo. La investigación documental se utilizó para seleccionar elementos teóricos, conocer las políticas y acciones del Estado en cuanto a pesca, obtener estadísticas y recabar información. La investigación de campo fue el medio para lograr acercamientos al universo de estudios. Se puede concluir que tomando en cuenta la particularidad de la actividad pesquera, en tanto ésta depende en mayor medida que otras actividades productivas a las condiciones climáticas y a los ciclos de abundancia y escasez de especies, que la actividad requiere ser intensiva en las temporadas propicias.
\end{abstract}

Palabras clave: pesquerías ribereñas, cooperativas pesqueras, permisionarios, especies marinas.

\begin{abstract}
This article will present the results of the research performed on the forms of organization and production of the fisheries in the Baja California and its degree of development. It also analyzes the participation of government agencies regarding the process of consolidation, development, specific requirements of these fisheries, and the kind of support they give to low commercial value fishing and the mass consumption. This work used two types of research: documented and field research. Documented research was used to select the theoretical elements, learn about the policies and actions of the Government regarding fishing, obtain statistics, and gather information. Field research was the mean used to reach this universe of studies. We can get to the conclusion that due to the fact that fishing activity depends more on the climatic conditions and on the cycles of abundance and scarcity of species than other productive activities, during the proper productive seasons, this activity needs to be performed with more intensity.
\end{abstract}

Keywords: Riverside fisheries, fishery cooperatives, concessionaries, marine species. 


\title{
PESQUerias Ribereñas en baja California *
}

\author{
Por \\ Ana María Avilés Muñoz \\ $y$ \\ Leticia Figueroa Ramírez **
}

\section{INTRODUCCION}

A lo largo de la costa occidental del estado de Baja California existen campos pesqueros que se localizan en la parte o extensión de la playa en donde ocurre la pesca de ribera, y el área donde habitualmente se asienta la población que participa en las pesquerías ribereñas. En algunos campos se observan espacios habitacionales e infraestructura para la producción; en otros en cambio, se identifica únicamente la presencia de equipo, artes y pescadores. No obstante ciertos estudiosos registran una cantidad considerable de campos. ${ }^{1} \mathrm{La}$ investigación de las pesquerías de la cual se deriva este artículo sólo detectó alrededor de veinte (ver figura 1). Sin embargo, de ninguna manera se cuestiona la existencia de otros, fundamentalmente porque en su mayoría son transitorios o se ubican en lugares de difícil acceso. Ahora bien, independientemente de la localización del campo o de sus características, puede afirmarse la presencia de algún tipo o tipos de pesquería de ribera.

Las pesquerías ribereñas constituyen unidades productivas pesqueras de ribera localizadas en áreas colindantes con el mar. ${ }^{2}$ La pesca cambia a la denominación de pesquería cuando se acciona bajo principios de captura definidos, con determinados medios y con cierta regularidad en la pesca. Comúnmente opera sobre hases comerciales y de subsistencia, y mantiene la actividad en relación con las temporadas de captura. ${ }^{3}$

En sentido amplio, la pesquería se refiere a un grupo de unidades de pesca que se dedica a un mismo tipo de captura y que conforma una determinada forma de producción pesquera ribereña. Además, por extensión, la pesquería incluye “. . la forma en que se dispone del

\footnotetext{
- Este artículo es un subproducto del reporte terminal de investigación “La pesca en los ecusistemas costeros y sus relaciones con la plataforma continental de Baja California”. La investigación se realizó en el Instituto de Investigaciones Sociales de la Universidad Autónoma de Baja California, de agosto de 1983 a diciembre de 1985 .

** Licenciadas en Sociología. Investigadoras del Instituto de Investigaciones Sociales de la Universidad Autónoma de Baja California.

I Se identificaron 80 campos pesqueros. Aguayo, L.A., El sector pesquero en el estado de Baja California. $\mathrm{s} / \mathrm{p}$.

2 Ley Federal para el Fomento de la Pesca, art. 11, p. 11.

${ }^{3}$ Bottemanne, C.J., Economia de la pesca, p. 17.
} 


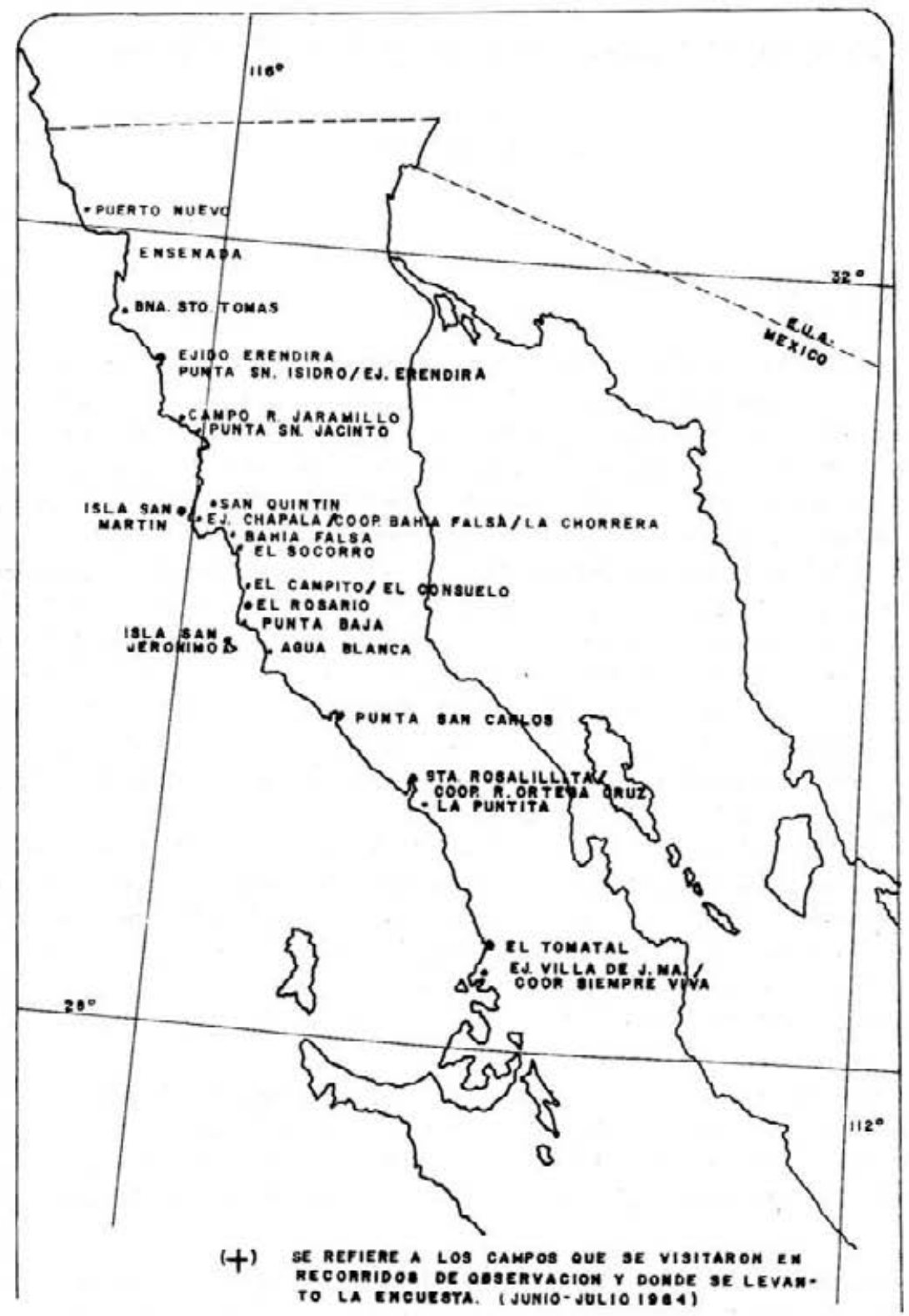

FIGURA 1.

FUENTE: IIS.UABC. "La pesca en los ecosistemas costeros y sus relaciones con la plataforma continental de Baja California" encuesta a la población ribereña, costa occidental dei estado de Baja California. 
pescado desembarcado por tal grupo de unidades y el modo en que es procesado eventualmente en tierra". ${ }^{4} \mathrm{Si}$ se considera el concepto en este sentido, se puede establecer que una pesquería es a su vez una industria pesquera. $^{5}$

Las pesquerías se dedican a la explotación de especies del mar sus. ceptibles de capturarse con pangas y artes de pesca sencillas, en agua del mar territorial. ${ }^{6}$ Los medios de pesca que incluyen las artes, embarcaciones, motores, métodos de preservación y auxiliares accionados a través del esfuerzo humano constituyen, en su combinación, la pesquería. ${ }^{7}$

De la definición anterior, la característica que no fue posible deter. minar en el contexto ribereño en estudio, se refiere a que las pesquerías operan: ". . . comúnmente. . sobre bases. . . de subsistencia. .." (vid. supra). Lo anterior se justifica con los tres tipos de pesquería que se pudieron detectar, y que en ningún caso evidencian tal característica. Las pesquerías ribereñas a las que aludimos corresponden a la pesquería de permisionarios, la de productores por su cuenta, y la de sociedades cooperativas. Enseguida conviene incorporar las definiciones operacionales o de trabajo de estas pesquerías, con la intención de observar semejanzas y diferencias entre lo teórico y la realidad.

A la pesquería de permisionarios se le define como al conjunto de unidades productivas pesqueras de ribera, integradas por personas físicas o morales que se dedican a la explotación de especies del mar con fines de lucro. El ejercicio de esta pesquería se supedita a permisos y renovación en los términos que indica la Ley de Pesca en los artículos 25 y $29 . .^{8}$

La pesquería de productores por su cuenta, comprende a unidades productivas pesqueras de ribera integradas por personas físicas que se dedican a la explotación de especies del mar con fines de lucro. ${ }^{9}$ Esta pesquería no tiene permiso legal para la captura. Existe la propiedad de medios de producción y se comercializa el producto directamente por la pesquería, o a través de las unidades pesqueras que tienen permiso para capturar. ${ }^{10}$

La pesquería ribereña de sociedades cooperativas en cambio, corresponde a unidades de producción pesquera que se integran a su vez, con un mínimo de $80 \%$ de socios pescadores ribereños de la clase trabajadora, residentes en municipios colindantes con el mar. Los socios de estas cooperativas aportan su trabajo personal, efectivo, bienes o derechos

\footnotetext{
Ibid., p. 18.

'Loc, cit.

- Ley Federal para el Fomento de la Pesca, art. 11.12, p. 11.

7 Bottemanne, C.J. Ob cit., p. 18.

${ }^{8}$ Ley Federal para el Fomento de la Pesca, art. 8, pp. 9-10 y arts. 25, 29, pp. 17-19.

I Ibid., art. 8, pp. 9.10.

10 Recorridos de observación y encuesta. Proyecto "La pesca en los ecosistemas costeros y sus relaciones con la plataforma continental de Baja California", Instituto de Investigaciones Sociales, UABC. Mexicali, B.C., agosto-octubre de 1983 y junio-julio de 1984.
} 
bajo principios de igualdad de derecho y obligaciones. La sociedad no persigue fines de lucro. Utiliza trabajadores asalariados sólo bajo determinadas circunstancias. Una particularidad adicional, consiste en que se reserva a las cooperativas pesqueras la captura o explotación de las especies de abulón, langosta de mar, ostión, camarón, totoaba, almeja pismo y tortuga marina. ${ }^{11}$

El presente artículo tiene como objetivos establecer los resultados de la investigación sobre las formas de organización y producción de estas pesquerías, grado de desarrollo y participación del Estado en relación con el proceso de consolidación, desarrollo, requerimientos específicos de las pesquerías y estímulos para la generación de productos pesqueros de bajo valor comereial o de consumo mayoritario.

Antes de entrar a los resultados del análisis, cabe puntualizar que se tomó en cuenta la particularidad de la actividad pesquera, en tanto se supedita en mayor medida que otras actividades productivas a las condiciones climáticas y a los ciclos de abundancia y escasez de especies. En consecuencia, la actividad requiere de ser intensiva en las temporadas propicias. Esta situación estuvo presente en varios aspectos del análisis; como por ejemplo, en la estimación de los volúmenes de producción y de las jornadas de trabajo, entre otros, ya que la encuesta se aplicó entre los meses de junio-julio de 1984 .

\section{FORMAS DE ORGANIZACION Y PRODUCCION PREDOMINANTES}

Los elementos principales en el análisis de las formas de organización y producción corresponden a las relaciones de producción que existen en las pesquerías, mismas que se identifican con variables relacionadas con la propiedad de los medios, distribución del producto, composición de la población pesquera, ingreso y formas de pago.

\section{PESQUERIAS DE PERMISIONARIOS Y PRODUCTORES POR SU CUENTA}

A través del análisis de las variables anteriores se pudo determinar que tanto la pesquería de permisionarios como la de productores por su cuenta expresan relaciones de producción capitalista, o en otras palabras, corresponden a la forma de organización y producción capitalista.

El carácter de la propiedad y del trabajo en estas pesquerías se define, tanto en forma de producción capitalista, como privado. Este carácter se demuestra por un lado, en los altos porcentajes de propiedad de equipo y artes en la población de permisionarios y productores por su

11 Ley General de Sociedades Cooperativas, análisis de los articulos 1, 34-35, 56, 62, pp. $101,110$. 115-116 y Ley Federal para el Fomento de la Pesca, artículos 49, 52, pp. 28-29. 
cuenta; y por el otro, en los bajos porcentajes de propiedad sobre estos medios que presenta la población asalariada de ambas pesquerías, debido a la relativa importancia de los medios en propiedad, ya que son de fácil adquisición y/o elaboración (cuadro 1).

El carácter privado de la propiedad determina además, el carácter de la población involucrada, que origina población propietaria de medios como son los permisionarios y productores por su cuenta y población no propietaria, como son los asalariados. En otras palabras, el carácter privado determina la composición de la población pesquera y conduce a la diferenciación de la población entre propietaria y asalariada o no propietaria (cuadro 2 ).

El comportamiento de la propiedad repercute además, en el ingreso de la población. En este sentido, los propietarios de los medios obtienen los mayores ingresos a diferencia de los asalariados (ver figuras 2-4), no obstante que éstos presentan ingresos altos si se comparan con las poblaciones asalariadas de otras actividades. En lo que atañe a las formas de pago prevalece el porcentaje de la venta o comisión que se puede considerar como pago a destajo. Cabe agregar que esta forma de pago está intimamente ligada a la forma de producción capitalista y a la vez la forma de pago más generalizada en la actividad ribereña.

Otra peculiaridad de la coincidencia de estas pesquerías con la producción capitalista, se refiere a la división del trabajo. Si bien es cierto que en la captura se observa una incipiente división de las actividades, el hecho de que la población se dedique a más de una, simultáneamente, permite indicar que la delimitación de las operaciones en esta actividad no se encuentra definida como operaciones independientes a las que esté ligada la población.

En el procesamiento en cambio, no obstante la población, realiza más de una actividad; no las lleva a cabo de manera simultánea como sucede en la captura, lo cual indica que en las actividades de procesamiento existe una división del trabajo mucho más definida. Esta división sin lugar a dudas manifiesta parte de la esencia capitalista que tiende, en la medida de su desarrollo, a una profunda división del trabajo.

Otra manifestación sustancialmente capitalista se refiere al desplazamiento de la población entre los campos pesqueros, que si bien existe en razón de la movilidad de las especies marinas, expresa a su vez, necesidades del capital, que por un lado requiere de capturar especies de alto valor y por el otro, de fuerza de trabajo libre disponible. En el cuadro 3 pueden identificarse núcleos de población definidos que proveen a las pesquerías, al observar los porcentajes de población que reside fuera de los grupos donde se les localizó y los principales puntos de residencia.

Con los elementos expuestos hasta aquí es factible comparar el comportamiento de las formas de producción y organización capitalista de las pesquerías de permisionarios y de productores por su cuenta, con las 


\section{CUADRO 1. Propiedad del equipo y artes por tipo de población y pes- quería:}

\begin{tabular}{|c|c|c|c|c|c|c|c|c|c|c|c|c|c|c|}
\hline \multirow{4}{*}{ EQUIPO Y AKTES } & \multicolumn{4}{|c|}{$\begin{array}{l}\text { SOCIEDADES COOPERATIVAS } \\
\text { DE PHODLCCION PESOUERA }\end{array}$} & \multicolumn{6}{|c|}{ PERMISIONARIOS } & \multicolumn{4}{|c|}{$\begin{array}{c}\text { PRODUCTORES POR SU } \\
\text { CUENTA }\end{array}$} \\
\hline & \multirow{2}{*}{\multicolumn{2}{|c|}{$\begin{array}{l}\text { Asalariado } \\
\text { Propiedad }\end{array}$}} & \multirow{2}{*}{\multicolumn{2}{|c|}{$\begin{array}{c}\text { Cooperati- } \\
\text { vista }\end{array}$}} & \multirow{2}{*}{\multicolumn{2}{|c|}{\begin{tabular}{|l|} 
Asalariado \\
Propiedad \\
\end{tabular}}} & \multirow{2}{*}{\multicolumn{2}{|c|}{\begin{tabular}{|l} 
Productor \\
por su eta.
\end{tabular}}} & \multirow{2}{*}{\multicolumn{2}{|c|}{\begin{tabular}{|c|}
$\begin{array}{c}\text { Cooperati- } \\
\text { vista' }\end{array}$ \\
Propiedad \\
\end{tabular}}} & \multirow{2}{*}{\multicolumn{2}{|c|}{\begin{tabular}{|l|} 
Asalariado \\
Propiedad \\
\end{tabular}}} & \multirow{2}{*}{\multicolumn{2}{|c|}{$\begin{array}{l}\text { Productor } \\
\text { por su cla. }\end{array}$}} \\
\hline & & & & & & & & & & & & & & \\
\hline & Si & No & $\mathrm{Si}$ & No & Si & No & $\mathrm{Si}$ & No & $\mathrm{Si}$ & No & Si & No & $\mathrm{Si}$ & No \\
\hline Panga & 0.0 & 100.0 & 17.0 & 83.0 & 0.0 & 100.0 & 97.7 & 2.3 & 40.0 & 60.0 & 0.0 & 100.0 & 78.6 & 21.4 \\
\hline Moter & 0.0 & 100.0 & 18.9 & 81.1 & 0.0 & 100.0 & 97.7 & 2.3 & 40.0 & 60.0 & 0.0 & 100.0 & 78.6 & 21.4 \\
\hline Compresor & 0.0 & 100.0 & 29.5 & 70.5 & 4.3 & 95.7 & 75.0 & 25.0 & 0.0 & 100.0 & 10.0 & 90.0 & 71.4 & 28.6 \\
\hline Remos & 5.9 & 94.1 & 30.0 & 70.0 & 6.6 & 93.4 & 95.3 & 4.7 & 40.0 & 60.0 & 11.8 & 88.2 & 91.7 & 8.3 \\
\hline Equipo de buzo & 10.0 & 90.0 & 38.5 & 61.5 & 20.8 & 79.2 & 83.3 & 16.7 & 0.0 & 100.0 & 0.0 & 100.0 & 60.0 & 40.0 \\
\hline Trasmallo & 0.0 & 100.0 & 21.6 & 78.4 & 5.3 & 94.7 & 100.0 & 0.0 & 40.0 & 60.0 & 12.5 & 87.5 & 81.8 & 18.2 \\
\hline Red de chinchorro & 0.0 & 0.0 & 4.8 & 95.2 & 12.5 & 87.5 & 100.0 & 0.0 & 0.0 & 100.0 & 0.0 & 100.0 & 0.0 & 0.0 \\
\hline Red agallera & 0.0 & 100.0 & 20.7 & 79.3 & 12.5 & 87.5 & 100.0 & 0.0 & 0.0 & 100.0 & 0.0 & 100.0 & 30.0 & 50.0 \\
\hline Red caguamera & 16.7 & 83.3 & 10.5 & 89.5 & 25.0 & 75.0 & 100.0 & 0.0 & 33.3 & 66.7 & 0.0 & 0.0 & 0.0 & 0.0 \\
\hline Red curvinera & 0.0 & 100.0 & 15.0 & 85.0 & 0.0 & 100.0 & 100.0 & 0.0 & 0.0 & 0.0 & 0.0 & 100.0 & 80.0 & 20.0 \\
\hline Red chango & 0.0 & 0.0 & 0.0 & 0.0 & 0.0 & 100.0 & 0.0 & 0.0 & 0.0 & 0.0 & 0.0 & 0.0 & 0.0 & 0.0 \\
\hline Palangre o palangar & 0.0 & 100.0 & 30.8 & 69.2 & 29.2 & 70.8 & 80.0 & 20.0 & 0.0 & 100.0 & 0.0 & 100.0 & 75.0 & 25.0 \\
\hline Trampas & 25.0 & 75.0 & 39.8 & 60.2 & 29.0 & 71.0 & 87.5 & 12.5 & 0.0 & 0.0 & 33.3 & 66.7 & 77.8 & 22.2 \\
\hline Gancho & 18.2 & 81.8 & 41.0 & 59.0 & 20.5 & 79.5 & 96.0 & 4.0 & 50.0 & 50.0 & 18.2 & 81.8 & 66.7 & 33.3 \\
\hline Hawaiana (fisga) & 33.3 & 66.7 & 53.7 & 46.3 & 19.0 & 81.0 & 66.7 & 33.3 & 0.0 & 0.0 & 25.0 & 75.0 & 100.0 & 0.0 \\
\hline Lavas & 13.3 & 86.7 & 37.9 & 62.1 & 27.8 & 72.2 & 77.8 & 22.2 & 0.0 & 100.0 & 25.0 & 75.0 & 100.0 & 0.0 \\
\hline Instrumentos de captura ${ }^{2}$ & 12.5 & 87.5 & 26.5 & 73.5 & 5.3 .3 & 46.7 & 100.0 & 0.0 & 0.0 & 0.0 & 0.0 & 100.0 & 100.0 & 0.0 \\
\hline Instrumentos de procesamicnto ${ }^{1}$ & 0.0 & 100.0 & 0.0 & 100.0 & 66.7 & 33.3 & 100.0 & 0.0 & 0.0 & 0.0 & 0.0 & 0.0 & 0.0 & 0.0 \\
\hline Racas & 0.0 & 100.0 & 6.3 & 93.7 & 0.0 & 100.0 & 0.01 & 100.0 & 0.0 & 0.0 & 0.0 & 0.0 & 0.0 & 0.0 \\
\hline Tridente & 50.0 & 50.0 & 52.6 & 47.4 & 0.0 & 100.0 & 100.0 & 0.0 & 0.0 & 0.0 & 0.0 & 0.0 & 0.0 & 0.0 \\
\hline
\end{tabular}

I Población que en esta pesqueria guarda una relaeión de asalariada y se analiza como ul, no obstante pertenecer a alguna soeiedad cooperativa.

2Comprende: anzurlo, marana, boyas, anclas, cuehilla, carrete o piola de anzuelo, matadores, machete, filamento, chumaceras, arraneador, botas, mandil, impermeable, plomos, brüjula, costal, tubo para buceo, curricán y tarraya.

'Compreade; pinzas, guantes, cucharas, canasta, tabla. gorra, plástico, balanza. rebanadora, picadora. lavadora, baldes, palas, medida para lanzosta. costal. eepillo y piola.

FUENTE: IIS-UABC. Proyecto "La pesca en los ecosistemas costeros y sus relaciones coe le plataforma continental de Baja California", encuesta a la población ribereña, junio-julio de I984, eosta occidental del catado de Baja Californio.

- Poreentajes respecto a la cantidad de equipo y artes en propiedad, por tipo de población en cada pesqueria. 
CUADRO 2. Clasificación de la población pesquera ribereña.

\begin{tabular}{lrr}
\hline \multicolumn{1}{c}{ TIPO DE POBLACION } & ABS & $\%$ \\
\hline Asalariado & 153 & 42.6 \\
Productor por su cuenta & 57 & 15.9 \\
Trabajador familiar (sin retribución) & 1 & 0.3 \\
Cooperativista & 145 & 40.4 \\
Permisionario & 3 & 0.8 \\
TOTAL & 359 & 100.0 \\
\hline
\end{tabular}

- Incluye a cinco cooperativas que guardan una relación de asalariados, dentro de la pesquería de permisionarios.

FUENTE: IIS-UABC, Proyecto "La pesca en los ecosistemas costeros y sus relaciones con la plataforma continental de Baja California", encuesta a la población ribereña, junio-julio de 1984, costa occidental del estado de Baja California.

definiciones operativas de estas unidades de producción anotadas párrafos antes, y observar que la realidad de estas pesquerías no expresa variantes importantes respecto al contenido de las definiciones, en tanto que se basan en el principio de propiedad, y el objetivo principal de estas formas de producción es el lucro o ganancia.

Por otro lado, a partir de los mismos elementos de análisis se determina que la pesquería ribereña de sociedades cooperativas corresponde a la forma de organización y producción cooperativa.

\section{PESQUERIA DE SOCIEDADES COOPERATIVAS}

El carácter de la propiedad y del trabajo en esta pesquería se expresa como colectivo. Este carácter se manifiesta, por un lado, en bajos porcentajes de propiedad respecto al equipo y en relación con las artes; la propicdad estriba en trampas, ganchos, hawaiana o fisga, javas y tridente que son artes fáciles de elaborar o de adquirir (vid. supra cuadro 1). Por otro lado, el carácter colectivo se sustenta en el principio cooperativista colectivo sobre la propiedad, el trabajo y la producción, para que, a partir del trabajo que aportan los cooperativistas en común, se logre una distribución equitativa de las ganancias en relación con la capacidad de trabajo en cada uno.

No obstante esta pesquería se fundamenta en el principio colectivo de la propiedad y su población manifiesta bajos porcentajes en este renglón, es posible establecer que la pesquería no se ajusta de manera estricta al principio antes mencionado. Lo anterior se justifica a partir de la coexistencia de diferentes formas de producción que derivan, en el caso 
CUADRO 3. Desplazamiento de la población: campo de origen y principales lugares de residencia.

\begin{tabular}{|c|c|c|c|}
\hline Campo de origen ${ }^{1}$ & $\begin{array}{l}\text { Población que } \\
\text { reside fuera } \\
\text { del campo }\end{array}$ & $\begin{array}{l}\text { Principales lugares de } \\
\text { residencia }^{2}\end{array}$ & \\
\hline Puerto Nuevo & $100 \%$ & Tijuana & $93.8 \%$ \\
\hline Bocana Santo Tomás & $100 \%$ & $\begin{array}{l}\text { Ensenada } \\
\text { Ej. Uruapan }\end{array}$ & $\begin{array}{l}37.5 \% \\
37.5 \%\end{array}$ \\
\hline Punta San Jacinto & $100.0 \%$ & $\begin{array}{l}\text { Tijuana } \\
\text { Ensenada-Maneadero } \\
\text { Camalú } \\
\text { C.R. Jaramillo } \\
\text { Punta Colonet }\end{array}$ & $\begin{array}{l}16.7 \% \\
33.4 \% \\
16.7 \% \\
16.6 \% \\
16.6 \%\end{array}$ \\
\hline Bahía Falsa & $100.0 \%$ & Ensenada & $61.1 \%$ \\
\hline La Puntita & $100.0 \%$ & Ensenada & $76.5 \%$ \\
\hline Punta San Carlos & $100.0 \%$ & $\begin{array}{l}\text { El Rosario } \\
\text { Ensenada }\end{array}$ & $\begin{array}{l}37.5 \% \\
16.6 \%\end{array}$ \\
\hline Agua Blanca & $100.0 \%$ & EI Rosario & $100.0 \%$ \\
\hline El Tomatal & $92.6 \%$ & Ejido Eréndira & $36.0 \%$ \\
\hline El Campito/El Consuelo & $84.6 \%$ & El Rosario & $72.7 \%$ \\
\hline C.R. Jaramillo & $70.6 \%$ & $\begin{array}{l}\text { Punta Colonet } \\
\text { Ensenada }\end{array}$ & $\begin{array}{l}66.7 \% \\
25.0 \%\end{array}$ \\
\hline Punta Baja & $22.2 \%$ & El Rosario & $75.0 \%$ \\
\hline $\begin{array}{l}\text { Santa Rosalillita/Cooperativa } \\
\text { Rafael Ortega Cruz }\end{array}$ & $18.9 \%$ & San Quintín & $42.9 \%$ \\
\hline $\begin{array}{l}\text { El Rosario/Cooperativa En- } \\
\text { senada, Unidad El Rosario }\end{array}$ & $10.4 \%$ & $\begin{array}{l}\text { Ensenada } \\
\text { Ejido Uruapan }\end{array}$ & $\begin{array}{l}40.0 \% \\
40.0 \%\end{array}$ \\
\hline $\begin{array}{l}\text { Ej. Chapala/Cooperativa } \\
\text { Bahía Falsa/La Chorera }\end{array}$ & $9.1 \%$ & San Quintín & $100.0 \%$ \\
\hline $\begin{array}{l}\text { Punta San Isidro/Unidad } \\
\text { de Prod. Pesquera, Ejido } \\
\text { Eréndira }\end{array}$ & $4.3 \%$ & Ensenada & $100.0 \%$ \\
\hline $\begin{array}{l}\text { Ej. Villa de Jesís María/ } \\
\text { Cooperativa Siempre Viva }\end{array}$ & $3.0 \%$ & Tijuana & $100.0 \%$ \\
\hline El Socorro & $0.0 \%$ & & \\
\hline
\end{tabular}

${ }^{1}$ El campo de origen se refiere al campo pesquero donde se localizó a la población.

${ }^{2}$ El porcentaje que aparece junto a (los) lugar (es) de residencia, es la proporción de la población que no habita en el campo y reside en la localidad mencionada. 


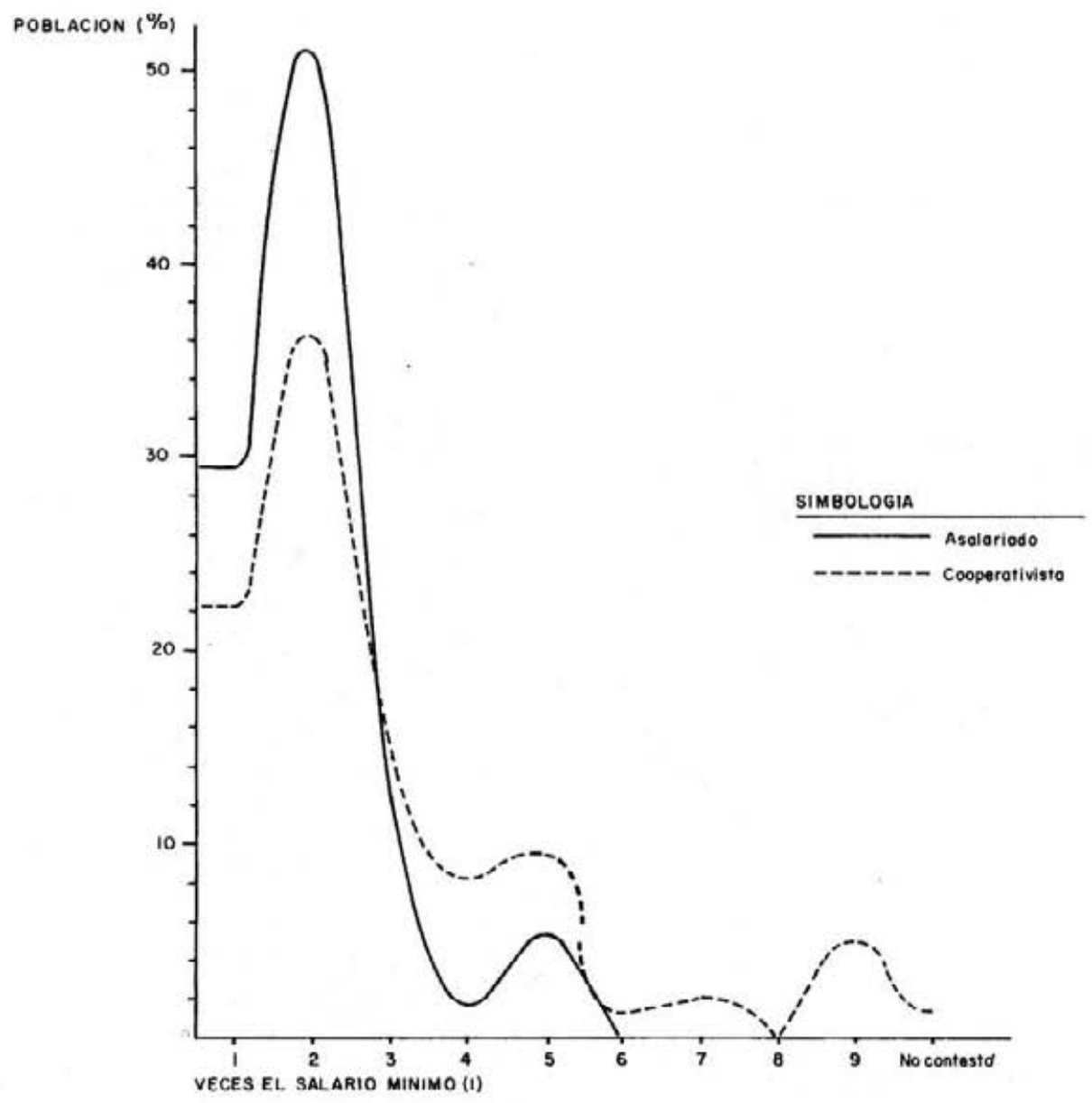

FIGURA 2. Ingreso mensual por tipo de población y pesquería: sociedades cooperativas de producción pesquera.

- Corresponde al salario minimo general mensual a la fecha de encuesta. FUENTE: Cuadro 17-1-A. 


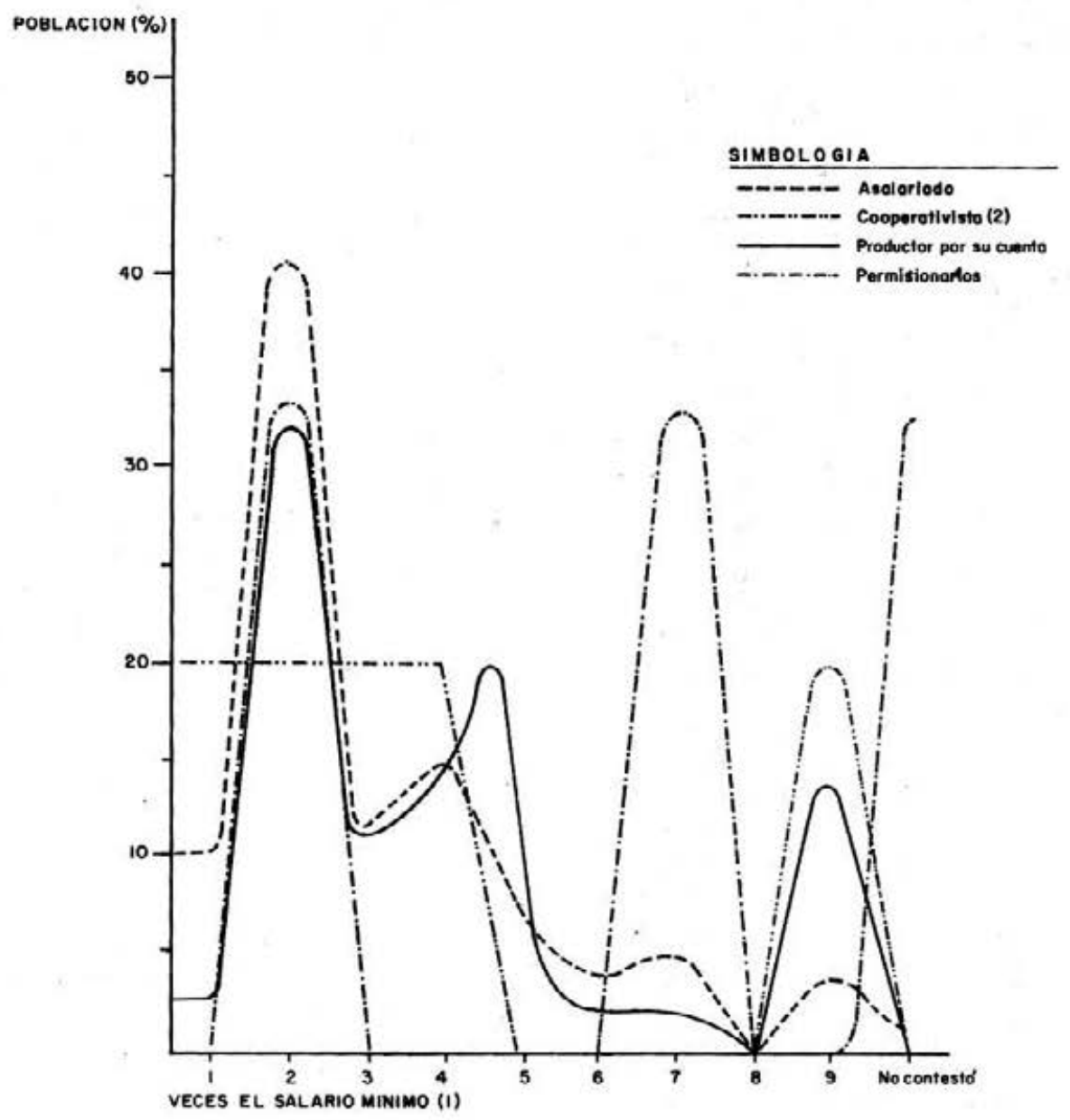

\section{FIGURA 3. Ingreso mensual por tipo de población y pesquería: permisionarios.}

1 Corresponde al salario minimo general mensual a la fecha de encuesta.

2 Incluye a cinco cooperativas que guardan una relación de asalariados, dentro de la pesquería de permisionarios.

FUENTE: Cuadro 17-2-A. 


\section{Ana María Avilés Muñoz y Leticia Figueroa Ramírez}

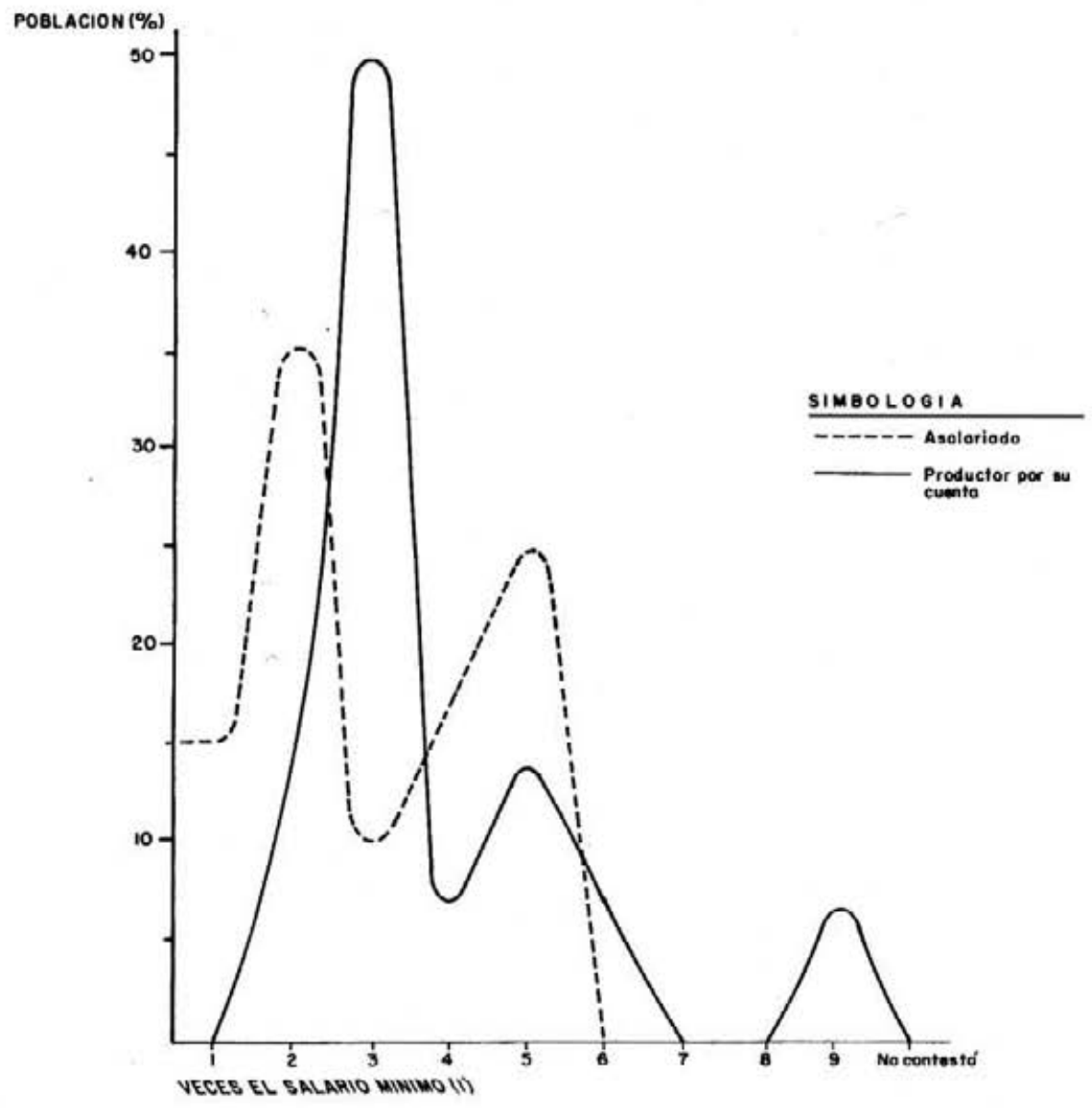

FIGURA 4. Ingreso mensual por tipo de población y pesquería: productores por su cuenta.

- Corresponde al salario minimo general mensual a la fecha de encuesta.

FUENTE: Cuadro 17-3-A. 
de las pesquerías de ribera, en el carácter privado y colectivo de la propiedad y del trabajo, lo que ocasiona que la forma de producción predominante - en este caso la capitalista-, imprima a las otras formas condiciones que les son ajenas. Esta situación se ejemplifica con una parte de la población cooperativista que se detenta como propietaria de los medios.

Es indudable que la situación antes descrita prevalece en esta pesquería. Sin embargo, son de propiedad colectiva los medios de producción más importantes, como los que se refieren a las instalaciones e infraestructura y la mayor parte del equipo básico de captura como las pangas, motores y compresores.

Cabe decir que el carácter colectivo de la propiedad determina asimismo el carácter de la población involucrada, que se refleja en el $71.1 \%$ de población cooperativista. Si se considera el principio colectivo sobre la propiedad como base del trabajo y producción, no debe existir el trabajo asalariado en las cooperativas; no obstante, el $28.9 \%$ restante de la población de esta pesquería es asalariada. Esta situación puede explicarse, en parte, si se toma en cuenta que la Ley General de Sociedades Cooperativas prevé la presencia o utilización de trabajadores asalariados en las cooperativas bajo determinadas circunstancias, en cuyo caso corresponde a las mismas, definir el momento en que incorporan esta fuerza de trabajo.

En relación con el ingreso y formas de pago se encontraron dos de éstas. Las cooperativistas perciben ingreso a través del porcentaje de la venta o comisión, a diferencia de la población asalariada cuya forma de pago más importante es a través del salario fijo. Ambas formas de pago se identifican con la forma de producción capitalista.

En lo que toca al monto de los ingresos se observa que en esta pesquería son, en general, menores a los del resto de las pesquerías. Sin embargo, la población cooperativista percibe ingresos más altos que la población asalariada (vid. supra figuras 2-4).

Respecto a la división técnica del trabajo, al igual que en las otras formas de producción ribereña, se realizan tareas simultáneas en la captura; no así en el procesamiento, donde la actividad está más definida. Cabe decir que en la captura la población cooperativista registra los más altos porcentajes como jefes de panga y que algunos cooperativistas tienen por su cuenta trabajadores asalariados.

En lo que atañe al desplazamiento de la población, la cooperativista se desplaza más que la asalariada, situación que se explica en parte por la diversidad de campos que se consideran áreas de las cooperativas y por las características de la actividad que precisa el desplazamiento en busca del producto (cuadro 3 ).

Tomando en consideración los datos anteriores en relación con el comportamiento de la pesquería de cooperativas en estudio, es posible 
sostener que las diferencias principales con la definición operacional de esta pesquería estriban en que: $a$ ) la pesquería de sociedades cooperativas no se ajusta de manera estricta al principio colectivo de la propiedad y, $b$ ) la composición de la población difiere de las estipulaciones legales en tanto el porcentaje de cooperativistas es menor que el $80 \%$ legal establecido, $y$ alto en relación con la población asalariada.

\section{FORMAS DE PRODUCCION Y GRADO DE DESARROLLO CAPITALISTA}

El conocimiento de las formas de organización y producción de las pesquerías ribereñas constituye el antecedente para el análisis del grado de desarrollo de las mismas. Esta consideración se deriva de la vinculación entre el modo de producir los bienes materiales en la sociedad y las relaciones de producción que se generan y corresponden a su vez a un determinado desarrollo de las fuerzas productivas. ${ }^{12}$

Respecto al grado de desarrollo de las pesquerías se consideró la categoría de análisis "desarrollo de las fuerzas productivas y de las relaciones sociales de producción", que incluye variables en relación con la concentración asalariada, socialización del trabajo, acervo de capital y tecnología; grado de vinculación con el mercado interior y exterior y desplazamiento de la población como fuerza de trabajo libre.

El análisis de las variables anteriores permite definir a la pesquería de permisionarios, como la de mayor grado de desarrollo capitalista en los campos ribereños del área de estudio. Cabe aclarar que para efectos del análisis del grado de desarrollo capitalista de las pesquerías, únicamente se consideraron las formas de organización y producción capitalistas, que en los campos ribereños corresponden a las pesquerías de permisionarios y de productores por su cuenta, en la medida en que la de sociedades cooperativas muestra rasgos que corresponden tanto a esta forma de producción como de la cooperativista.

El análisis de la concentración de la fuerza de trabajo y del tipo de población involucrada en la pesquería de permisionarios, fundamenta la afirmación de que esta pesquería presenta el mayor grado de desarrollo capitalista en la medida en que la población involucrada es casi en su totalidad -a excepción de los permisionarios-, población asalariada. En otras palabras, tanto los asalariados, como los cooperativistas y pro. ductores por su cuenta de esta pesqueria, guardan una relación de asalariados.

Por otra parte, puede decirse que la población permisionaria detenta la propiedad de los medios ya sea equipo, artes, instalaciones e infraestructura. De esta manera, los permisionarios deben considerarse

${ }^{12}$ Marx, Karl, Introducción general a la crítica de la economia politica 1857. p. 66. 
como los propietarios propiamente dicho, lo cual no significa que los productores por su cuenta en mayor medida que los asalariados de esta pesquería, no tengan en propiedad parte del equipo y artes, y en ningún caso, instalaciones e infraestructura.

Para determinar que la concentración de fuerza de trabajo asalariada y la propiedad de los medios presentan mayor grado de desarrollo en la pesquería de permisionarios, conviene recordar que la pesquería de productores por su cuenta no tiene la misma magnitud que la población asalariada y además, presenta porcentajes menores en la propiedad de medios, esto es, equipo y artes - sobre todo de equipo indispensable para la actividad-, a diferencia de los permisionarios (vid. supra cuadro 1).

En lo que atañe al ingreso, en ambas pesquerías la población asalariada percibe ingresos menores en relación con los de la población propietaria de los medios - permisionarios y productores por su cuenta-; situación que sin lugar a dudas alude a la forma de organización y producción capitalista, que también se observa en la forma de pago que predomina en estas pesquerías (vid. supra figuras 3-4).

En relación con la división técnica del trabajo, tanto la pesquería de permisionarios como la de productores por su cuenta presentan una incipiente división en las actividades de captura y las que se consideran de procesamiento, íntimamente ligadas a la captura. Esto quiere decir que no se manifiesta un proceso de transformación del producto que vaya más allá de operaciones de fileteo, secado de sargazo y corte de tenazas entre otras, que incluso se realizan en el área donde se lleva a cabo la captura. Es notorio entonces, el incipiente desarrollo en la división del trabajo en esta actividad. Por otra parte, se aprecia una importante diferencia de la participación en actividades de captura y de procesamiento por parte de la población propietaria de los medios, productores por su cuenta y permisionarios, fundamentalmente porque los primeros participan directamente en estas actividades, en contraste con los segundos que no lo hacen.

Aún cuando la división técnica y social del trabajo manifiesta un desarrollo primario en estas pesquerías, existe un aspecto íntimamente relacionado con la división técnica que corresponde al dominio de artes, equipo y accesorios e instrumentos de trabajo. Es importante puntualizar que en las pesquerías, el dominio tiene que ver con la utilización de los medios. En este sentido, la pesquería de permisionarios presenta una intensa utilización en equipo y artes, y en la pesquería de productores por su cuenta, una también intensa utilización en equipo, pero débil en relación con las artes.

Por otra parte, para examinar el grado de desarrollo a través de la jornada de trabajo, se tomó en cuenta que la duración de la jornada patentiza la explotación de la fuerza de trabajo, de manera tal que, a mayor duración, mayor explotación y consecuentemente, mayor identifi- 
cación con el comportamiento capitalista. Las jornadas más largas en estas pesquerías, que van de 7 a 8,9 a 10 y 11 a 12 horas diarias, tienen porcentajes más altos en la pesquería de permisionarios.

Cuando se trata de conocer el grado de desarrollo a través de las actividades alternativas de la población, es preciso decir que a menor incoporación o menores porcentajes de la población ribereña en actividades alternativas a la pesca, mayor avance capitalista. Lo anterior parte de considerar que el desarrollo de éste, tiende a concentrar en una sola actividad a la población trabajadora.

Por lo anterior, cabe decir que la pesquería de permisionarios presenta más alto grado de desarrollo al registrar, en comparación con la pesquería de productores por su cuenta, un menor porcentaje de su población en actividades alternativas a la pesca y además, los permisionarios no participan en actividades alternativas como sucede en parte de la población de los propios productores por su cuenta.

Aún cuando el desplazamiento de la población ribereña obedece en primera instancia al movimiento del producto, el desplazamiento obedece, por otro lado, a las necesidades del capital; tanto de la búsqueda de especies de alto valor o mayores volúmenes de otras especies, como de fuerza de trabajo disponible. Este comportamiento expresa sin lugar a dudas, relaciones capitalistas en el área y actividad ribereña, de tal modo que es en la pesquería de permisionarios donde se observa de manera más sensible este comportamiento.

Otro elemento importante que permite conocer el grado de desarrollo capitalista en la actividad ribereña se refiere al volumen y diversidad de especies de captura. La pesquería de permisionarios explota mayores volúmenes de captura en relación con la pesquería de productores por su cuenta, aún cuando la captura está en relación con las mismas especies. Cabe agregar que el promedio de meses de captura es ligeramente mayor en la de permisionarios (cuadros 4 y 5 e infra cuadro 6).

En relación con las especies marinas corresponde analizar la distribución del producto (especies) entre productores y el destino de éste. La población de la pesquería de permisionarios que trabaja por su cuenta, entrega casi el $100 \%$ del producto directamente a éstos, no así en la pesquería de productores por su cuenta, en la que la distribución se diversifica más. Esto significa que la pesquería de permisionarios tiene mayor control sobre el producto, lo cual manifiesta el tipo de relaciones que predominan en esta pesquería, donde el producto en realidad interesa como objeto de cambio y no como objeto de uso para la población.

Por otro lado, el comportamiento del destino de las especies es indicador del nivel de desarrollo de las pesquerías debido a que a través de este análisis, es factible observar la expansión del mercado, y de manera indirecta, el valor de las especies; la expansión del mercado en tanto el destino del producto sea el mercado nacional o el extranjero, y el 
CUADRO 4. Volumen de captura diaria y anual por especies y tiempo de captura, por pesquería.

\begin{tabular}{lrrr}
\hline $\begin{array}{c}\text { P E R M I S I O N A R I O S } \\
\text { E S P E C I E S }\end{array}$ & $\begin{array}{r}\text { Volumen diario } \\
\text { (kg por viaje) }\end{array}$ & $\begin{array}{c}\text { Meses de } \\
\text { captura } \\
(\bar{X})\end{array}$ & $\begin{array}{r}\text { Volumen anual } \\
\text { (toneladas) }\end{array}$ \\
\hline Langosta & 280 & 7.10 & 18.7 \\
Abulón & 160 & 3.60 & 5.4 \\
Jaiba & 1,752 & 8.79 & 144.6 \\
Erizo & 902 & 7.30 & 61.8 \\
Jurel & 5,595 & 5.43 & 285.2 \\
Lenguado y mero & 4,325 & 6.59 & 267.6 \\
Cabrilla, cocinero, corvina aleta amarilla & 2,700 & 6.64 & 168.3 \\
Baqueta, bacalao & 40 & 4.00 & 1.5 \\
Almeja, ostión, choro y mejillón & 40 & 12.00 & 13.6 \\
Pescado blanco, mojarra y pámpano & 2,028 & 8.07 & 153.6 \\
Sierra, tiburones, rayas y corvina plateada & 6,885 & 9.45 & 610.9 \\
Rocot y vieja & 3,376 & 7.90 & 250.4 \\
Chano, berrugata, bonita, macarela & 3,275 & 4.20 & 129.1 \\
Lisa & 32 & 5.67 & 1.7 \\
Plantas acuáticas & 3,329 & 7.86 & 245.7 \\
Tortuga & 0 & 0.00 & 0.0 \\
Roncador, chopa & 30 & 3.00 & 0.8 \\
Pulpo & 0 & 0.00 & 0.0 \\
& & & \\
T O T A L & 34,749 & 6.76 & $2,358.9$ \\
\hline & & & \\
\hline
\end{tabular}

'Incluye: gelidium, gigartina, pelo de cochi y lechuguilla.

${ }^{2}$ Se estimó a partir del volumen diario de cada renglón de especie (s) entre la población por panga (tres), por el promedio de días de trabajo en buen tiempo de la pesquería y el promedio de meses de captura por renglón.

FUENTE: IIS.UABC, Proyecto "La pesca en los ecosistemas costeros y sus relaciones con la plata. forma continental de Baja California", encuesta a la población ribereña, junio-julio de 1984, costa occidental del estado de Baja California.

valor de las especies, considerando que las de alto valor son las que se exportan en más altos porcentajes.

La pesquería de permisionarios exporta algunas especies de alto valor a Estados Unidos de Norteamérica y a Japón. Otras las orienta al mercado nacional junto con la diversidad de especies de menor valor. Además, esta pesquería vende ciertas especies directamente al público.

La pesquería de productores por su cuenta en cambio, comercializa el producto con los permisionarios, cooperativistas, restaurantes, turismo, y también lo expende directamente. Del porcentaje del producto que expende esta pesquería se desconoce el destino. No obstante ser una mera conjetura, existe la posibilidad de que parte de este producto se exporte. 


\section{CUADRO 5. Volumen de captura diaria y anual por especies y tiempo de captura, por pesquería.}

\begin{tabular}{lrrr}
\hline $\begin{array}{l}\text { PRODUCTORES POR SU CUENTA } \\
\text { E S P E C I E S }\end{array}$ & $\begin{array}{c}\text { Volumen diario } \\
\text { (kg por viaje) }\end{array}$ & $\begin{array}{c}\text { Meses de } \\
\text { captura } \\
(\mathbf{X})\end{array}$ & $\begin{array}{r}\text { Volumen anual } \\
\text { (toneladas) }\end{array}$ \\
\hline Langosta & 739 & 5.26 & 35.4 \\
Abulón & 116 & 3.25 & 3.4 \\
Jaiba & 534 & 8.23 & 40.0 \\
Erizo & 238 & 3.12 & 6.8 \\
Jurel & 705 & 3.57 & 22.9 \\
Lenguado y mero & 1,055 & 6.69 & 64.2 \\
Cabrilla, cocinero, corvina aleta amarilla & 659 & 8.09 & 48.5 \\
Baqueta, bacalao & 151 & 7.00 & 9.6 \\
Almeja, ostión, choro y mejillón & 1,060 & 4.00 & 115.4 \\
Pescado blanco, mojarra y pámpano & 170 & 5.50 & 8.5 \\
Sierra, tiburones, rayas y corvina plateada & 995 & 8.35 & 75.6 \\
Rocot y vieja & 975 & 6.68 & 59.3 \\
Chano, berrugata, bonita, macarela & 1,160 & 6.66 & 70.3 \\
Lisa & 0 & 0.00 & 0.0 \\
Plantas acuáticas ${ }^{1}$ & 1,850 & 3.88 & 65.3 \\
Tortuga & 0 & 0.00 & 0.0 \\
Roncador, chopa & 15 & 2.00 & 0.3 \\
Pulpo & 40 & 12.00 & 4.4 \\
& & & \\
T O T A L & 10,462 & 6.23 & 629.9 \\
\hline
\end{tabular}

\footnotetext{
${ }^{1}$ Incluye: gelidium, gigartina, pelo de cochi y lechuguilla.

${ }^{2}$ Se estimó a partir del volumen diario de cada renglón de especie (s) entre la población por panga (tres), por el promedio de días de trabajo en buen tiempo de la pesquería y el promedio de meses de captura por renglón.

FUENTE: IIS.UABC, Proyecto "La pesca en los ecosistemas costeros y sus relaciones con la plataforma continental de Baja California”, encuesta a la población ribereña, junio-julio de 1984, costa occidental del estado de Baja California.
}

Por lo anterior puede decirse que la pesquería de permisionarios expresa un grado de desarrollo mayor en relación con la expansión del mercado y valor de las especies.

Al considerar los medios de producción de ambas pesquerías, resulta más importante la de permisionarios en relación con la cantidad y capacidad del equipo como panga y motores y en algunas artes, como trasmallos y chinchorros. Asimismo, en el equipo de buzo existen diferencias importantes entre las pesquerías, con un registro más alto en la pesquería de permisionarios. En este sentido y en referencia a otros medios como las instalaciones e infraestructura, únicamente la de permisionarios tiene frigorificos, almacenes, thermokines, una plataforma, expendios para el 
producto, galerones para trabajar y congeladores. A pesar de que la pesquería utiliza por debajo de su capacidad la mayoría de estos medios con un tiempo de trabajo promedio anual de 9.7 meses, las fuerzas productivas respecto a los medios presentan mayor nivel de desarrollo sobre todo en lo que a los últimos se refiere. Ya que la pesquería de productores por su cuenta no tiene en existencia ningún tipo de instalaciones o infraestructura.

La inversión es otro elemento indispensable en la determinación del grado de desarrollo. Sin embargo, el análisis de la inversión no es susceptible de comparación entre estas pesquerías por haberse excluido del análisis a la pesquería de productores por su cuenta, debido a los montos poco significativos de inversión reportada.

No obstante lo anterior, es necesario señalar la importancia de la pesquería de permisionarios en la inversión pesquera, que si se compara con la inversión de la pesquería de sociedades cooperativas es 2.9 veces mayor.

Considerando que el desarrollo económico es a su vez ". . . el desplazamiento hacia arriba de todo el sistema social. .., ${ }^{13}$ que incluye entre otros aspectos los niveles de vida de la población, se compararon algunos medios de vida de la población en estas pesquerías. De manera muy general se puede decir que la población de la pesquería de permisionarios goza de niveles de bienestar más elevados que la población de la pesquería de productores por su cuenta, lo cual refleja en los niveles de escolaridad, en el mayor acceso a servicios médicos, porcentajes más altos en lo que concierne a la propiedad de la vivienda y a la vivienda en préstamo, mismas que están construidas con muros de block o de ladrillo y servicios de agua corriente y electrificación en porcentajes más altos que las viviendas de la población pesquera de productores por su cuenta. Además, las viviendas de la pesquería de los permisionarios están mejor ubicadas en relación con el acceso a centros de abasto, a servicios públicos como pavimentación, alumbrado público, transporte urbano y a clínicas médicas y/o dispensarios.

\section{LA PARTICIPACION DEL ESTADO EN LAS PESQUERIAS}

La ingerencia del Estado en la producción ribereña, se plantea a partir de su participación en la economía como una función estructuralmente definida. En este sentido se consideran las acciones del Estado orientadas a garantizar las condiciones generales de la producción y a definir la actividad pesquera como una actividad prioritaria nacional. Se trata de una intervención del Estado estructuralmente articulada en la

13 Acosta Romero, Salvador, "Crecimiento o desarrollo económico" en Boletín del Instituto de Estudios Sociales de la Universidad de Guadalajara, p. 23. 
reproducción de las sociedades capitalistas, es decir, reproducción de un orden de contradicciones, no de su eliminación, sino de su mantenimiento dentro de los límites del orden. ${ }^{14}$

En relación estrecha con el desarrollo que expresen las pesquerías se encuentra la participación del Estado. La propuesta del estudio en este sentido se refiere a que a mayor ingerencia del Estado, menor grado de desarrollo en términos capitalistas de las pesquerías; y a menor ingerencia, mayor grado de desarrollo.

Las políticas del Estado acerca del desarrollo se explicitan ampliamente en el Plan Nacional de Desarrollo. En este documento el Estado expresa su interés por ". . las aspiraciones y objetivos de la sociedad. . . ${ }^{15}$ El Estado como autoridad que regula la participación de los sectores social y privado en la producción, debe asimismo, accionarse en todos los requerimientos del proceso productivo. ${ }^{16}$

Lo anterior ofrece elementos para establecer que las diferencias en el grado de desarrollo de las pesquerías se deben en parte a la intervención del Estado. Por ejemplo, obras de infraestructura pesquera como rampas, plataformas para secado del producto, galerones de trabajo y plantas de electrificación, se han proporcionado a las sociedades cooperativas a través del Estado. La pesquería de permisionarios únicamente cuenta con plat aformas para secado y galerones de trabajo que ha adquirido por iniciativa propia.

El apoyo del sector público en acciones directamente productivas que se expresan en almacenes o frigoríficos, se han canalizado a las cooperativas. De entre los permisionarios se declaró haber sido favorecidos únicamente a través de un permiso para utilizar un cuarto frío que es propiedad de una cooperativa. Existen, sin embargo, apoyos indirectos del sector público para el resto de las pesquerías, como los caminos de terracería que, independientemente de haberse construido con un propósito determinado, proporcionan servicio a todas las unidades de producción. Asimismo, en relación con el financiamiento preferencial y con la economía pesquera, las acciones del Estado favorecen a la pesquería de sociedades cooperativas.

Lo hasta aquí expuesto permite sostener la relación entre la menor ingerencia del Estado con el mayor desarrollo de las pesquerías en términos capitalistas, en tanto el grado de desarrollo de las pesquerías de permisionarios y de productores por su cuenta - que por otro lado constituyen formas de producción capitalistas-, se obtiene, independientemente de la ingerencia del Estado en la producción ribereña.

\footnotetext{
14 Alvater Elmar, "Notas sobre algunos problemas del intervencionismo del Estado" en El Estado en el capitalismo contemporáneo, pp, 94-101, 105, 107-13 y Poder Ejecutivo Federal, Plan Nacional de Desarrollo 1983-1988, p. 147.

15 Poder Ejecutivo Federal, Plan Nacional de Desarrollo 1983-1988, p. 147.

${ }^{16}$ Ibid., p. 306.
} 
Además de las acciones del Estado en infraestructura, financiamiento y asesoría técnica, existen otras que se orientan a lograr la consolidación de las pesquerías.

En la consolidación, se parte de una concepción del Estado que se orienta a lograr cohesión, integración, solidez y dinamismo a la organización productiva ribereña a través de un conjunto de factores o elementos. En este sentido, el Estado trata de combinar integral y equilibradamente a los ". . . diversos sectores, elementos, intereses, necesídades que . . ." 17 inciden en la producción pesquera. Esta situación incluye la importancia de la participación del sector social y privado.

En las pesquerías en estudio se observa un apoyo abierto del Estado a la pesquería de sociedades cooperativas en aspectos de la producción. En cambio, el resto de las pesquerías prácticamente carece de este apoyo. Tal comportamiento impide un proceso de consolidación del sector pesquero ribereño en su conjunto.

Lo anterior se patentiza a través del apoyo del sector público a las sociedades cooperativas, manifiesto de la manera siguiente: 1) el Estado concesiona a las cooperativas la explotación y exportación de especies de alto valor comercial; 2) proporciona obras de infraestructura y equipamiento de manera exclusiva a esta pesquería; 3 ) las políticas de crédito preferencial benefician en el $100 \%$ a las cooperativas; 4 ) las asesorías técnicas en materia pesquera proporeionada por el Estado, favorecen en mayor número a la población de la pesquería de cooperativas; 5 ) en relación con la organización social de la producción, el Estado regula en las cooperativas los agentes o elementos que participan en el proceso productivo y la relación de propiedad con respecto a los medios de producción.

\section{NIVEL DE CONGRUENCIA}

Respecto a la congruencia entre las características que asume el proceso de producción ribereña y los requerimientos de la economía en su conjunto, se detectaron tres comportamientos principales; $a$ ) la pesca ribereña de la costa occidental de Baja California produce especies para el consumo humano directo y en esa medida responde a una prioridad nacional, e incluye especies de alto y bajo valor comercial; $b$ ) en relación a la producción de especies para el consumo mayoritario como otra prioridad nacional, la pesca ribereña es importante como oferente, no obstante, el sector público no apoya a la pesquería ribereña de permisionarios en esta producción, a pesar de que en Baja California esta pesquería obtiene la producción más elevada de estas especies; $c$ ) en la pesca ribereña no se respetan de manera rigurosa las disposiciones legales en materia pesquera como son las relativas a la zona de reserva de cultivos, de refugio de especies, de explotación, de épocas y zonas de veda, etcétera.

${ }^{17}$ Ibid., p. 305. 
Por otro lado puede afirmarse, que en la pesca ribereña se requiere de mayor congruencia entre las políticas y acciones del Estado y las condiciones y necesidades de las pesquerías, que se reflejan sobre todo en las acciones en infraestructura, equipamiento, financiamiento y asesoría técnica.

Tocante a lo anterior, se observó que aún cuando el Estado dota de infraestructura y equipamiento a las sociedades cooperativas a través de obras como fábricas de hielo, bodegas, procesadoras, enlatadoras, cocedoras, plantas de electrificación, desaladoras, varaderos, rampas, plataformas, caminos, etc., existe una subutilización y capacidad ociosa, principalmente por el promedio anual de trabajo de esta pesquería (nueve meses), temporadas de captura que varía según la especie, y obras que no se utilizan o se utilizan por debajo de su capacidad.

Una de las causas más importantes de la incongruencia entre las políticas del Estado y las condiciones y necesidades de las pesquerías se resume en que el Estado no atiende en la misma magnitud a éstas, hecho que repercute en una situación preferencial para la pesquería de sociedades cooperativas, que propicia ciertos comportamientos como capturas clandestinas de especies de alto valor comercial o beneficios en asesoría técnica, exclusivamente a cierto sector de la población ribereña.

\section{OFERTA DE PRODUCTOS PARA LAS MAYORIAS}

En lo que atañe al menor nivel de congruencia entre las políticas pesqueras que acciona el Estado y la inadecuada oferta de productos del mar para los grupos mayoritarios, se observa que no obstante los planes pesqueros proponen ciertos volúmenes de producción para el consumo humano, y en especial para el popular, no se logran en la realidad; lo cual es fácilmente observable en la producción pesquera de Baja California. Como ya se señaló, la producción pesquera ribereña se orienta casi exclusivamente a especies de consumo humano; sin embargo, la preferencia en la producción corresponde a especies de alto valor. Aunado a lo anterior, los volúmenes de captura de las pesquerías aún son insuficientes, afirmación que es posible sustentar con el volumen de producción ribereño a 1984, que no alcanzó las 11,000 toneladas (vid. supra cuadros 4 y 5 e infra cuadro 6).

De la diversidad de especies que se explotan en las pesquerías de ribera del área de estudio se consideraron de consumo popular dentro de la clasificación de escama, a las cabrillas, cocinero, pescado blanco, corvina plateada, mojarra, rocot, vieja, chano, berrugata, barracuda, boca dulce, chopa o chopita y roncador. La clasificación de tiburones y rayas comprende a la cornuda, gata, perro, cazón, guitarra, gavilán, angelito, rayas, mantarrayas y a las que se les conoce en general como tiburones. Las otras especies definidas como de bajo valor son: el jurel, pámpano, lisa, sierra, bonita y macarela. 
CUADRO 6. Volumen de captura diaria y anual por especies y tiempo de captura por pesquería.

\begin{tabular}{|c|c|c|c|}
\hline $\begin{array}{l}\text { SOCIEDADES COOPERATIVAS } \\
\text { DE PRODUCCION PESQUERA } \\
\text { ESPECIES }\end{array}$ & $\begin{array}{l}\text { Volumen diario } \\
\text { (kg por viaje) }\end{array}$ & $\begin{array}{l}\text { Meses de } \\
\text { captura } \\
(\bar{X})\end{array}$ & $\begin{array}{l}\text { Volumen amual } \\
\text { (toneladas) }^{2}\end{array}$ \\
\hline Langosta & 8,282 & 5.84 & 454.1 \\
\hline Abulón & 1,366 & 4.63 & 59.4 \\
\hline Jaiba & 1,185 & 5.18 & 57.6 \\
\hline Erizo & 2,281 & 4.52 & 96.8 \\
\hline Jurel & 2,775 & 4.91 & 127.9 \\
\hline Lenguado y mero & 4,555 & 5.49 & 234.8 \\
\hline Cabrilla, cocinero y corvina aleta amarilla & 5,127 & 4.96 & 238.8 \\
\hline Baqueta y bacalao & 0 & 0.0 & 0.0 \\
\hline Almeja, ostión, choro y mejillón & 16,572 & 8.66 & $4,042.3$ \\
\hline Pescado blanco, mojarra y pámpano & 3,116 & 6.59 & 192.8 \\
\hline Sierra, tiburones, rayas y corvina plateada & 9,260 & 5.10 & 443.4 \\
\hline Rocot y vieja & 5,318 & 6.91 & 345.0 \\
\hline Chano, berrugata, bonita y macarela & 955 & 5.90 & 52.9 \\
\hline Lisa & 3,430 & 6.87 & 221.2 \\
\hline Plantas acuáticas ${ }^{1}$ & 17,860 & 5.09 & 853.5 \\
\hline Tortuga & 6 & 2.0 & 0.1 \\
\hline Roncador, chopa & 0 & 0.0 & 0.0 \\
\hline Pulpo & 0 & 0.0 & 0.0 \\
\hline TOT A L & 82,088 & 5.6 & $7,420.6$ \\
\hline
\end{tabular}

'Incluye: gelidium, gigartina, pelo de cochi y lechuguilla.

${ }^{2}$ Se estimó a partir del volumen diario de cada renglón de especie (s) entre la población por panga (tres), por el promedio de días de trabajo en buen tiempo de la pesquería y el promedio de meses de captura por renglón.

FUENTE: IIS-UABC, Proyecto "La pesca en los ecosistemas costeros y sus relaciones con la plataforma continental de Baja California", encuesta a la población ribereña, junio-julio de 1984, costa occidental del estado de Baja California.

Otra variable que influye en una baja producción de las especies mencionadas, corresponde a la baja rentabilidad que representa esta producción.

Si se toma en cuenta que las especies de consumo mayoritario tienen menor valor en el mercado, que existen otras especies de alto valor en los campos pesqueros que además tienen demanda en el mercado extranjero, y consecuentemente, adquieren más valor, es indiscutible que la producción ribereña prefiera la producción de estas últimas, sobre todo si recordamos que el objetivo principal de la producción capitalista tiende a la búsqueda del mayor plusvalor o ganancia posible. En este sentido, la posibilidad de que la producción de especies para el consumo mayoritario 
represente una baja rentabilidad para las pesquerías, no se aleja de la realidad como lo demuestra el comportamiento del valor comercial, volúmenes de captura y destino de la producción ribereña.

El análisis de dichos elementos indica que: a) las pesquerías ribereñas orientan el $88.8 \%$ de la producción total a especies de consumo humano directo en las que se encuentran especies de alto y bajo valor comercial; $b$ ) no obstante las pesquerías contribuyan con el total y con altos porcentajes de producción de algunas especies para el consumo popular en el estado, se puede decir que prefieren la producción de especies de alto valor, como lo evidencian el $55.1 \%$ de la producción de estas especies respecto a la producción total de las pesquerías; $c$ ) las pesquerías en el estado se dedican a la captura de langosta, abulón, lenguado, mero, almeja y ostión, entre otras consideradas como especies de alto valor comercial; $d$ ) en general, las especies de alto valor tienen demanda en el mercado exterior y las pesquerías las exportan en cantidades importantes; $e$ ) la pesquería que en más alto porcentaje produce especies para el consumo popular es la de permisionarios; $f$ ) la diferencia entre la especic de más bajo y más alto valor, es de 40 veces el valor; $g$ ) a pesar de observarse incrementos en la producción de especies de bajo valor en peso fresco y entero, en Baja California existen decrementos importantes en algunas especies que valdría la pena investigar, si se compara la producción de 1978 con la proyección de 1982-1984.

El comportamiento del valor comercial, volumen y destino de las especies de consumo mayoritario, ratifica la tendencia de la producción capitalista en relación con la obtención de mayor plusvalía, que se refleja en los volúmenes de captura de especies de alto valor.

Esta preferencia es un indicador de que la captura de especies de bajo valor comercial, significa baja rentabilidad. Sin embargo, es interesante observar que al incorporar la variable "inversión", como puede verse en el cuadro 7, al sumar los valores por tipo de especies, un porcentaje importante de inversión de ambas pesquerías se destina a la producción de especies de escama, de bajo valor y/o para el consumo mayoritario. Más que una contradicción, esto significaría que si bien la captura de especies de bajo valor susceptible para el consumo de grupos populares requiere mayor inversión, la 'preferencia' por especies de alto valor comercial se realiza con montos menores de inversión, que en el caso de permisionarios puede destinarse sobre todo a reposición de algún equipo y las artes, mientras que las cooperativas cuentan con el recurso de infraestructura.

Según la información que proporcionaron estas pesquerías, la inversión anual total asciende a $\$ 143^{\prime} 961,300.00$ de los cuales el $55.1 \%$ se destina a la producción de especies de alto valor y un $7.4 \%$ a especies para uso industrial.

Si se observa el comportamiento por pesqueria, la de sociedades cooperativas orienta el $\mathbf{9 3 . 5 \%}$ de la inversión a la producción de especies 
CUADRO 7. Inversión en la producción ribereña por pesquería (anual).

\begin{tabular}{|c|c|c|c|c|c|c|c|c|c|c|c|c|c|c|c|c|c|c|c|c|c|c|c|}
\hline \multirow[t]{2}{*}{$\begin{array}{l}\text { Pesque- } \\
\text { rin }\end{array}$} & \multirow[t]{2}{*}{ Especie } & \multirow{2}{*}{$\begin{array}{l}\text { Inversion total } \\
\text { (millones de } \\
\text { pesos) }\end{array}$} & \multirow{2}{*}{$100 \%$} & \multirow[b]{2}{*}{$73 \%$} & \multicolumn{3}{|c|}{$\begin{array}{l}\text { INVE R : } \\
\text { CAPTURA. }\end{array}$} & \multirow{2}{*}{$\begin{array}{l}10 \mathrm{~N} \\
\text { Nada }\end{array}$} & \multirow{2}{*}{$\begin{array}{l}\text { POR } \\
\text { No } \\
\text { sabe }\end{array}$} & \multicolumn{5}{|c|}{$\begin{array}{l}\text { A C T IVID A D } \\
\text { PROCESAMIENTO }\end{array}$} & \multirow[b]{2}{*}{ Nada } & \multirow[b]{2}{*}{$\begin{array}{l}\text { No } \\
\text { sabe }\end{array}$} & \multirow[b]{2}{*}{$100 \mathrm{~s}$} & \multicolumn{4}{|c|}{ COMERCINLIzaCion. } & \multirow{2}{*}{ Nada } & \multirow[b]{2}{*}{$\begin{array}{l}\text { No } \\
\text { sale }\end{array}$} \\
\hline & & & & & $50 \%$ & 25\% : & $\begin{array}{l}\text { Menos } \\
\text { de } 25\end{array}$ & & & $100 \%$ & $75 \%$ & $50 \%$ & $25 \%$ & $\begin{array}{l}\text { Menos } \\
\text { de } 25\end{array}$ & & & & $75 \%$ & $50 \%$ & $25 \%$ & $\begin{array}{l}\text { Menos } \\
\text { de } 25\end{array}$ & & \\
\hline \multirow{5}{*}{ 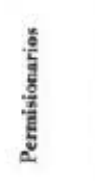 } & Abulán y erizo & $14,061.0$ & 0.0 & 50.0 & 50.0 & 0.0 & 0.0 & 0.0 & 0.0 & 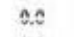 & 0.0 & 0.0 & 50.0 & 0.0 & 50.0 & 0.0 & 0.0 & 0.0 & 0.0 & 100.0 & 0.0 & 0.0 & 0.0 \\
\hline & Langosta y jaiba & 5.086 .3 & 33.3 & 33.3 & 33.4 & 0.0 & 0.0 & 0.0 & 0.0 & 0.0 & 0.0 & 0.0 & 33.3 & 0.0 & 66.7 & 0.0 & 0.0 & 0.0 & 0.0 & 66.7 & 0.0 & 33.3 & 0.0 \\
\hline & $\begin{array}{l}\text { Almeja, ostión, } \\
\text { choro y mej. }\end{array}$ & 720.0 & 0.0 & 100.0 & 0.0 & 0.0 & 0.0 & 0.0 & 0.0 & 0.0 & 0.0 & 0.0 & 0.0 & 0.0 & 100.0 & 0.0 & 0.0 & 0.0 & 0.0 & 100.0 & 0.0 & 0.0 & 0.0 \\
\hline & Escama & $77,030.8$ & 33.3 & 66.7 & 0.0 & 0.0 & 2.0 & 0.0 & 0.0 & 0.0 & 0.0 & 0.0 & 0.0 & 0.0 & 100.0 & 0.0 & 0.0 & 0.0 & 0.0 & 66.7 & 0.0 & 33.3 & 0.0 \\
\hline & Plantas acuatieas & $10,600,0$ & 0.0 & 0.0 & 100.0 & 0.0 & 0.0 & 0.0 & 0.0 & 0.0 & 0.0 & 0.0 & 100.0 & 0.0 & 0,0 & 0.0 & 0.0 & 0.0 & 0.0 & 100.0 & 0.0 & 0.0 & 0.0 \\
\hline \multirow{5}{*}{ 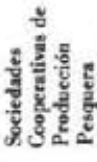 } & Abulón y erizo & 201.5 & 33.3 & 33.3 & 33.4 & 0.0 & 0.0 & 0.0 & 0.0 & 0.0 & 0.0 & 33.4 & 0.0 & 33.3 & 33.3 & 0.0 & 0.0 & 0.0 & 0.0 & 0.0 & 33.3 & 66.7 & 0.0 \\
\hline & Langusta y jailaa & $4,494.3$ & 20.0 & 60.0 & 0.0 & 0.0 & 0.0 & 0.0 & 20.0 & 0.0 & 0.0 & 0.0 & 20.0 & 20.0 & 40.0 & 20.0 & 0.0 & 0.0 & 0.0 & 20.0 & 20.0 & 40.0 & 20.0 \\
\hline & Almeja, ostión & $29,414.6$ & 33.3 & 33.3 & 0.0 & 0.0 & 0.0 & 0.0 & 33.4 & 0.0 & 0.0 & 0.0 & 0.0 & 33.3 & 33.3 & 33.4 & 0.0 & 0.0 & 0.0 & 0.0 & 33.3 & 33.3 & 33.4 \\
\hline & Earama & $2,352.8$ & 25.0 & 30.0 & 0.0 & 0.0 & 0.0 & 0.0 & 25.0 & 0.0 & 0.0 & 0.0 & 0.0 & 50.0 & 25.0 & 25.0 & 0.0 & 0.0 & 0.0 & 0.0 & 50.0 & 25.0 & 25.0 \\
\hline & Plantas acuátieas & 0.0 & 0.0 & 0.0 & 0.0 & 0.0 & 0.0 & 0.0 & 0.0 & 0.0 & 0.0 & 0.0 & 0.0 & 0.0 & 0.0 & 0.0 & 0.0 & 0.0 & 0.0 & 0.0 & 0.0 & 0.0 & 0.0 \\
\hline
\end{tabular}

- Se refiere a los montos de inversión declarados para cada actividad.

FUENTE: IISUABC, Proyecto - La pesea en los ecosistemas costeros y sus relaciones eon la plataforma contimental de Baja California", encucata a las unidades pre duetivas ribereñas, junio-julio de 1984, Ensenade, B.C. 
de alto valor; sin destinar inversión a las especies de uso industrial y apenas un 6.5\% a las de bajo valor. En la pesquería de permisionarios se invierte un $18.5 \%$ para la producción de especies de alto valor; $9.9 \%$ para las especies de uso industrial y $71.6 \%$ para las especies de bajo valor. Cabe decir que en el análisis del comportamiento de la inversión y del financiamiento, se excluye a la pesquería de productores por su cuenta por las razones que se exponen párrafos antes, y en el apartado sobre el grado de desarrollo capitalista de las pesquerías.

La pesquería de permisionarios destina inversión para especies de bajo valor, principalmente en la captura, y en menor medida, a la comercialización del producto. Ninguna cantidad se utiliza en el procesamiento de estas especies. Por su parte, la pesquería de sociedades cooperativas también invierte mayor cantidad en la captura, mientras que destina porcentajes semejantes en el procesamiento y comercialización.

En relación con el financiamiento, el total de las sociedades cooperativas tiene acceso a créditos de bajo interés, mientras que sólo el $11.1 \%$ de la pesquería de permisionarios disfrutan de este beneficio. ${ }^{18}$ Como puede verse en el cuadro 8, las sociedades cooperativas utilizan los créditos al $100 \%$, sobre todo los refaccionarios y de avío para compras de insumos, artes, maquinaria y reparaciones de equipo. Las instituciones financieras de apoyo son Banpesca y Banrural.

La pesquería de permisionarios utiliza créditos sólo en el $33.3 \%$ de los casos en la modalidad de crédito directo que tramitan a través de Banca Cremer y Banca Serfín. Por lo anterior, es evidente que el financiamiento público favorece a la pesquería de sociedades cooperativas, aunque no de la manera como los cooperativistas quisieran.

Finalmente, en resumen, las características y condiciones en que las pesquerías realizan la captura de especies para el consumo de las clases populares son: $a$ ) únicamente el $20 \%$ de las sociedades cooperativas tiene subsidio para la explotación de estas especies; $b$ ) el $100 \%$ de las cooperativas tienen el equipo de captura apropiado y el $60 \%$ de los permisionarios; c) el $60 \%$ de las cooperativas aceptan la existencia de estas especies en los campos pesqueros y únicamente el $20 \%$ de los permisionarios y, $d$ ) ambas pesquerías coinciden en un $80 \%$ en que existe demanda en el mercado para estas especies.

Por otro lado, las razones que dieron las pesquerías para no interesarse en una mayor captura de especies para consumo de clases populares tiene que ver, en el caso de las cooperativas, con la falta de mercado, escasez de las especies y por no dedicarse a esa explotación. Además, no les conviene invertir por ser tan variable la captura. Los permisionarios por su parte, señalan que les conviene más la explotación de otras especies

10 Encuesta a las unidades productivas ribereñas, junio-julio de 1984, Proyecto "La pesca en los ecosistemas costeros y sus relaciones con la plataforma continental de Baja California", Instituto de Investigaciones Sociales, Universidad Autónoma de Baja California. 
CUADRO 8. Características del crédito para la producción por pesquería.

\begin{tabular}{|c|c|c|c|c|c|c|c|c|}
\hline \multirow[t]{2}{*}{ Pesquería } & \multicolumn{2}{|c|}{$\begin{array}{l}\text { Utilización } \\
\text { del crédito }\end{array}$} & \multirow[b]{2}{*}{$\begin{array}{l}\text { Reface. } \\
\text { (compra } \\
\text { de maqui- } \\
\text { naria, re- } \\
\text { paración) }\end{array}$} & \multirow[b]{2}{*}{$\begin{array}{l}\text { de avío } \\
\text { compra } \\
\text { de insu- } \\
\text { mos y artes }\end{array}$} & \multicolumn{2}{|c|}{ Tipo de crédito * } & \multirow[b]{2}{*}{$\begin{array}{l}\text { Reface. } \\
\text { de avío y } \\
\text { directo }\end{array}$} & \multirow[b]{2}{*}{$\begin{array}{l}\text { No } \\
\text { procede }\end{array}$} \\
\hline & Si & No & & & Directo & $\begin{array}{l}\text { Reface. } \\
\text { y de } \\
\text { avío }\end{array}$ & & \\
\hline Permisionarios & 33.3 & 66.7 & 0.0 & 0.0 & 33.3 & 0.0 & 0.0 & 66.7 \\
\hline $\begin{array}{l}\text { Sociedades cooperativas } \\
\text { de producción pesquera }\end{array}$ & 100.0 & 0.0 & 60.0 & 20.0 & 0.0 & 0.0 & 20.0 & 0.0 \\
\hline
\end{tabular}

\begin{tabular}{|c|c|c|c|c|c|c|c|c|c|}
\hline \multirow[b]{2}{*}{ Banpesea } & \multicolumn{4}{|c|}{ Institución de crédito } & \multicolumn{4}{|c|}{ Opinión del crédito" } & \multirow[b]{2}{*}{$\begin{array}{l}\text { No } \\
\text { procede }\end{array}$} \\
\hline & Pider ** & Banrural & $\begin{array}{l}\text { Baneo } \\
\text { Cremer }\end{array}$ & $\begin{array}{l}\text { Banpesea } \\
\text { y Banrural }\end{array}$ & $\begin{array}{l}\text { Banca } \\
\text { Serfín }\end{array}$ & $\begin{array}{l}\text { No } \\
\text { procede }\end{array}$ & Agil & Lento & \\
\hline 0.0 & 0.0 & 0.0 & 22.2 & 0.0 & 11.1 & 66.7 & 33.3 & 0.0 & 66.7 \\
\hline 80.0 & 0.0 & 0.0 & 0.0 & 20.0 & 0.0 & 0.0 & 80.0 & 20.0 & 0.0 \\
\hline
\end{tabular}

- Los porcentajes corresponden a las respuestas de uso de eréditos.

* Programa Integral de Desarrollo Rural.

FUENTE: IIS.UABC, Proyecto "La pesca en los ecosistemas costeros y sus relaciones con la plataforma continental de Baja California", encuesta a las unidades productivas ribereñas, junio-julio de 1984, Ensenada, B. C. 
que no requieren de buen tiempo y de más horas de trabajo para su captura; asimismo, aducen que a estas especies se les encuentra en los campos más fácilmente en verano y además, porque el gobierno controla el precio, y no le conviene su captura.

Por último y en el sentido que se apunta antes, se puede decir que el comportamiento de la inversión por parte de las pesquerías, contradice las razones aducidas por éstas, ya que la captura de especies de bajo valor conduce a una baja rentabilidad en la producción en la medida que: a) el porcentaje anual más importante de inversión de las pesquerías, se destina a la producción de especies de bajo valor y/o para las mayorías y, $b$ ) la pesquería de permisionarios invierte $71.6 \%$ en la producción de estas especies. En cuanto al financiamiento, como se indicó, la pesquería de permisionarios tiene acceso a créditos de bajo interés en el 11.1\% a través de Banca Serfín, en comparación con el $100 \%$ de la pesquería de sociedades cooperativas que obtienen estos créditos a través de Banpesca y Banrural.

No obstante lo anterior, es innegable que las pesquerías ribereñas constituyen el canal más importante de oferta de productos de consumo humano y para las mayorías en el estado; principalmente la pesquería de permisionarios en la producción de especies para el consumo popular. Sin embargo, como se señaló párrafos atrás, los apoyos del sector público en materia de financiamiento y subsidios favorecen casi exclusivamente a la pesquería de cooperativas que es la oferente más débil de estas especies.

En el seguimiento del consumo aparente y per cápita de pescado fresco entero a nivel nacional y estatal, que se realizó en el proyecto de investigación, cabe destacar que las especies de consumo predominante son en esencia las de bajo valor. En este sentido, la oferta de las pesquerías ribereñas de estas especies, aunque limitada en volumen, adquiere particular importancia.

\section{APENDICE METODOLOGICO}

La estrategia metodológica para el logro del conocimiento de las pesquerías ribereñas en los rubros que cubre este artículo se dividió en dos aspectos principales: el primero se refiere a la manera de obordar el estudio de las pesquerías ribereñas en el área y el segundo, al método de análisis en relación a la participación del Estado en estas pesquerías.

La estrategia metodológica para el primer aspecto se inició con investigación de campo y documental para establecer definiciones operacionales o de trabajo de las pesquerías. Cabe decir que en un principio se trató de considerar a los pescadores libres como a un tipo de pesquería; lo cual no fue posible con base en que un asalariado puede ser a la vez un pescador libre. En su lugar, se optó por proponer a la pesquería de 
productores por su cuenta como una variante de las pesquerías que existen en el contexto ribereño, en la cual los pescadores son propietarios de los medios de producción, no obstante carecen de permiso para capturar. Esta pesquería por lo regular vende su producto a las pesquerías con permiso para la captura.

Para conocer las formas de organización y producción predominantes en los campos pesqueros, se analizaron las relaciones de producción existentes que conciernen a variables relacionadas con la propiedad de los medios, distribución del producto, composición de la población pesquera, ingreso y formas de pago. Para el análisis de las formas de organización como oferentes de productos para el consumo popular, se examina la rentabilidad de esta producción a través del volumen, valor comercial y destino del producto. Para efecto de este análisis, se clasificaron las especies que se capturan en razón del valor comercial.

Con respecto al grado de desarrollo de las pesquerías, se consideró la categoría de análisis, "desarrollo de las fuerzas productivas y de las relaciones sociales de producción", que incluye a variables relacionadas con la concentración asalariada, socialización del trabajo, acervo de capital y tecnología, grado de vinculación con el mercado interior y exterior, y desplazamiento de la población como fuerza de trabajo libre; todo esto, sin perder de vista el contexto que da especificidad o diferenciabilidad al fenómeno, aunado a la particularidad de la actividad pesquera en tanto se supedita, en mayor medida que otras actividades productivas, a las condiciones climáticas y a los ciclos de abundancia y escasez de especies. En consecuencia, la actividad requiere de ser intensiva en las temporadas propicias. Esta situación estuvo presente en varios aspectos del análisis como por ejemplo, en la estimación de los volúmenes de producción y en las jornadas de trabajo, entre otras.

En lo que toca al segundo aspecto sobre la participación del Estado en la producción ribereña en relación al proceso de consolidación, desarrollo y acciones que se vinculan con los requerimientos específicos de las pesquerías y, con los estímulos para la generación de productos pesqueros de bajo valor comercial, se planteó la participación del Estado en la economía como una función estructuralmente definida. En este sentido se consideran las acciones del Estado orientadas a garantizar las condiciones generales de la producción y a definir la actividad pesquera como una actividad prioritaria nacional. Se trata de una intervención del Estado estructuralmente articulada en la reproducción de las sociedades capitalistas; es decir, reproducción de un orden de contradicciones, no de su eliminación, sino de su mantenimiento dentro de los limites del orden. Bajo estas bases teóricas, se analizó la coincidencia o no entre las caracte. rísticas que asume el proceso de producción ribereño y las políticas y acciones del sector estatal relativas a la pesca y a los requerimientos de la economía en su conjunto. Para este análisis se realizó un ejercicio 
comparativo entre el contenido de los programas estatales y su aplicación en la realidad, que si bien resulta en un análisis de alguna manera parcial, justamente por prescindir de elementos como las circunstancias coyunturales, el aspecto legal y el marco temporal de los planes y programas, se consideró la manera más directa y ágil de observar el comportamiento.

La investigación se realizó a dos niveles: el documental y el de campo. La investigación documental se utilizó para: a) seleccionar los elementos teóricos que se consideraron más adecuados para el análisis; $b$ ) conocer las políticas y acciones del Estado en el sector pesca, particularmente en las pesquerías ribereñas; $c$ ) obtener información estadística sobre la actividad pesquera; $d$ ) localizar otras investigaciones con el mismo objeto de estudio; e) recabar información de documentos de archivo y, $f$ en la definición de las pesquerías ribereñas.

La investigación de campo fue el medio para los sucesivos acercamientos al universo de estudios. Se realizaron: a) tres recorridos de observación a los campos pesqueros con la finalidad de conocer el área, ubicar geográficamente a los campos, hacer los primeros registros de observación e iniciar el rapport con la población pesquera (agostooctubre de 1983); b) censo a la población pesquera de 17 campos (juniojulio de 1984), con una cédula de encuesta de 35 variables para cubrir los objetivos del proyecto y contrastar hipótesis; $c$ ) censo a las pesquerías de sociedades cooperativas (cinco) y encuesta a nueve permisionarios, a través de una cédula con 19 variables (junio-julio de 1984), para fines de los objetivos del proyecto y contrastar hipótesis sobre todo las relacionadas con la ingerencia del Estado en las pesquerías.

La estrategia del censo a la población ribereña se llevó a cabo como sigue: llegar al campo pesquero un día antes del censo, conversar con los pescadores y, al día siguiente, esperar la llegada de éstos entre 10:30 y 13:00 horas. Al bajar los pescadores de la panga, se les aplicaba la encuesta. Se censaron a 359 personas.

A las cooperativas se les censó en sus oficinas respectivas. A los nueve permisionarios que fueron encuestados se les localizó tanto en los campos pesqueros, como en sus domicilios particulares o en sus oficinas en la ciudad de Ensenada.

El contenido de las dos cédulas se sujetó a procesamiento computacional de acuerdo con el diseño de correlación de variables. Se pidió asimismo el coeficiente de contingencia $\mathrm{C}$ y la prueba de $\mathrm{X}^{2}$ para cada correlación. 


\section{BIBLIOGRAFIA}

ACOSTA Romero, Salvador. "Crecimiento o Desarrollo Económico", en Boletín del Instituto de Estudios Sociales de la Universidad de Guadalajara, julio-diciembre de 1981.

AGUAYO, L.A. El sector pesquero en el estado de Baja California. Instituto de Investigaciones Oceanológicas, Universidad Autónoma de Baja California, 1980.

ALVATER, Elmar. "Notas sobre algunos problemas del intervencionismo del Estado" en El Estado en el capitalismo contemporáneo, 3ra. Edic., Edit. Siglo XXI, México, 1980.

BOTTEMANE, C.J. Economía de la pesca. lra. reimpresión, Ed. Fondo de Cultura Económica, México, 1979.

MARX, Karl. Introducción a la critica de la economía política 1857, 16a. Edic., Ed. Pasado y Presente, México, 1982.

\section{LEYES Y DOCUMENTOS}

Ley Federal para el Fomento de la Pesca, Leyes y Códigos de México. Pesca, Edit. Porrúa, S.A., séptima edición, México, 1983.

Ley General de Sociedades Cooperativas, Leyes y Códigos de México, Sociedades Mercantiles y Cooperativas, Edit. Porrúa, trigesimosegunda edición, México, 1980.

Poder Ejecutivo Federal y Secretaría de Programación y Presupuesto, Plan Nacional de Desarrollo 1983-1988, 1ra. Edic. México, 1983. 